\title{
Effect of Multi-Sized Powder Mixture on Solid Casting and Sintering of Alumina
}

\author{
Kyeong-Sik Cho ${ }^{\dagger}$, Hyun-Kwuon Lee, and Jae-Hong Min \\ School of Advanced Materials Science and Engineering, Kumoh National Institute of Technology, Gumi 39177, Korea \\ (Received March 25, 2018; Revised April 26, 2018; Accepted April 26, 2018)
}

\begin{abstract}
The slip casting process is widely used to make green bodies from ceramic slips into dense compacts with homogeneous microstructure. However, stress may be generated inside the green body during drying, and can lead to cracking and bending during sintering. When starting from the spherical powders with mono-size distribution to make the close packed body, interstitial voids on octahedral and tetrahedral sites are formed. In this research, experiments were carried out with powders of three size types (host powder $(\mathrm{H})$, octahedral void filling powder $(\mathrm{O})$ and tetrahedral void filling powder $(\mathrm{T})$ ) controlled for average particle size by milling from two commercial alumina powders. Slips were prepared using three different powder batches from $\mathrm{H}$ only, $\mathrm{H}+\mathrm{O}$ or $\mathrm{H}+\mathrm{O}+\mathrm{T}$ mixed powders. After manufacturing green compacts by solid-casting, compacts were dried at constant temperature and humidity and sintered at $1650^{\circ} \mathrm{C}$. Alumina samples fabricated from the multi-sized powder mixture had improved compacted and sintered densities.
\end{abstract}

Key words : $\mathrm{Al}_{2} \mathrm{O}_{3}$, Slip casting, Milling, Sintering, Powders

\section{Introduction}

S olid casting, which uses a plaster mold, can be used to fabricate alumina powder with complex form into a dense compact. The starting powder conditions for high green body density fabrication were reported as $7: 1$ for the ratio of fine particles to coarse particles for a powder mixture of different sizes and a size difference of greater than 10 times. $^{1-8)}$ In this way, when the coarse powder fraction is high, despite attaining a high green body density, the sintering density decreases due to low densification driving force. Simultaneously, the particle size difference leads to densification of the fine particles first, resulting in the possibility of a non-uniform microstructure and density gradient induced cracks., ${ }^{5,-10)}$

Meanwhile, when there are optimum micro-filling monosize spherical particles, octahedral and tetrahedral voids are created for which the geometrical ratios of the void size to the host powder (H powder) are 0.414 and 0.225 , respectively. When the voids are filled sequentially, the filling fractions increase from $74.04 \%$ to $79.29 \%$ and $80.98 \%$ for the octahedral and tetrahedral voids, respectively.

In this study, commercial alumina powder was grinded using ball milling to increase the filling fraction of the green body and the powders corresponding to the void sizes of the host, 8-coordinated and 4-coordinated powders were prepared. Solid casting was then carried out for the multi-sized

\footnotetext{
${ }^{\dagger}$ Corresponding author : Kyeong-Sik Cho

E-mail : kscho@kumoh.ac.kr

Tel : +82-54-478-7737 Fax : +82-54-478-7769
}

powder mixture batches corresponding to the host +8 -coordinated and host +8 -coordinated +4 -coordinated powders, along with the mono-sized $\mathrm{H}$ powder batch. For the drying and sintering of the slip casted body containing the dispersion medium and organic matter, the humidity and temperature schedule has to be carefully controlled so that stress induced defects are not created. ${ }^{11-15)}$ Therefore, the process conditions were varied for the 3 size type mixture powder batches in order to allow comparative analysis of the drying characteristics, green body density microstructure, and sinterability after sintering at $1650^{\circ} \mathrm{C}$.

\section{Experimental Procedure}

\subsection{Alumina Raw Material and Grinded Powder}

For the alumina raw material, 2 commercial powders were used: SA-32 (Nippon Light Metal Co., Ltd. Japan) with an average size of $1.54 \mu \mathrm{m}$ and AES-11C (Sumitomo Chemical Industry, Japan) with an average size of $0.57 \mu \mathrm{m}$. The commercial alumina powders were of high purity (Table 1) and exhibited irregular polyhedral shapes (Fig. 1). Also, the

Table 1. Chemical Compositions of Raw Alumina Powder Provided by Supplier

\begin{tabular}{cccc}
\hline \multicolumn{2}{c}{ Alumina powder } & SA-32 & AES-11C \\
\hline & $\mathrm{Al}_{2} \mathrm{O}_{3}$ & 99.6 & 99.9 \\
Chemical & $\mathrm{MgO}$ & - & 0.05 \\
composition & $\mathrm{Na}_{2} \mathrm{O}$ & 0.37 & 0.04 \\
(wt\%) & $\mathrm{SiO}_{2}$ & 0.03 & 0.03 \\
& $\mathrm{Fe}_{2} \mathrm{O}_{3}$ & 0.02 & 0.01 \\
\hline
\end{tabular}




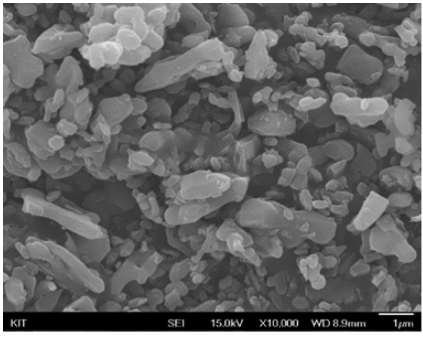

(a)

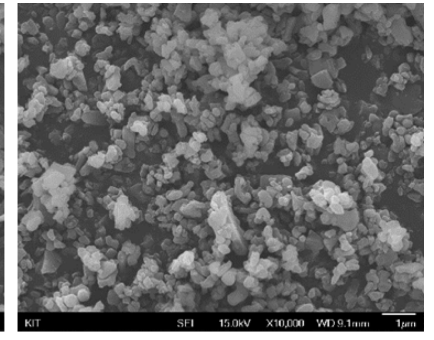

(b)
Fig. 1. Microstructures of raw alumina powder: (a) SA-32 and (b) AES-11C.

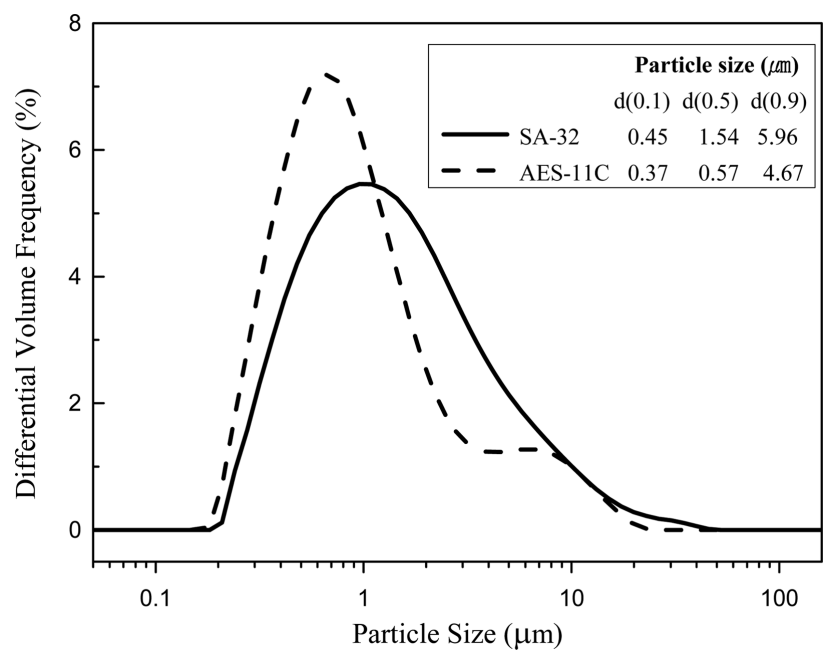

Fig. 2. Particle size distributions of raw alumina powder.

particle size distributions of the alumina powders were wide and close to a normal distribution, but more concentrated towards the smaller particle sizes (Fig. 2).

In order to produce optimum micro-filling green body using solid casting, the 2 commercial alumina powders were subjected to ball milling while controlling the average particle size for the intended and prepared spherical particle powders (Table 2). The SA-32 powder underwent $6 \mathrm{~h}$ of wet ball milling (average particle size $1.36 \mu \mathrm{m}$ ) to prepare the host powder (H powder). During the optimum micro-filling with spherical powder of the same size, the filling density can be increased by adding secondary and tertiary particles to the 6-coordinated octahedral voids and the 4-coordinated tetrahedral voids. The sizes of the secondary (O powder) and tertiary ( $\mathrm{T}$ powder) particles, calculated geometrically, were $0.56 \mu \mathrm{m}$ and $0.31 \mu \mathrm{m}$, respectively, with respect to the $\mathrm{H}$ powder size of $1.36 \mu \mathrm{m}$; the respective radius ratios to the $\mathrm{H}$ powder are 0.414 and 0.225 . The secondary and tertiary

Table 2. Starting Alumina Powders Processed by Ball Milling

\begin{tabular}{ccc}
\hline Nomination & Raw powder & Milling condition \\
\hline H powder & SA-32 & Wet ball milling for $6 \mathrm{~h}$ \\
O powder & SA-32 & Planetary milling for $2 \mathrm{~h}$ \\
T powder & AES-11C & Planetary milling for $9 \mathrm{~h}$ \\
\hline
\end{tabular}

Table 3. Alumina Powder Batches Mixed with Different Size Powders

\begin{tabular}{cccc}
\hline \multirow{2}{*}{ Nomination } & \multicolumn{3}{c}{ Mixing ratio (vol\%) } \\
\cline { 2 - 4 } & H powder & O powder & T powder \\
\hline Mono-sized batch & 100.00 & - & - \\
Double-sized batch & 93.47 & 6.53 & - \\
Triple-sized batch & 91.45 & 6.38 & 2.17 \\
\hline
\end{tabular}

powders were prepared by performing ball milling of the SA-32 and AES-11C powders, respectively, for 2 and $9 \mathrm{~h}$, at 300 rpm, using a planetary mill (Pulverisette 6, Fritsch, Germany).

By calculating the number ratio of geometric gaps during optimum micro-filling using mono-sized (H powder), doublesized $(\mathrm{H}+\mathrm{O}$ powder), and triple sized $(\mathrm{H}+\mathrm{O}+\mathrm{T}$ powder $)$ batches, the mixing ratios for the multi-sized powder mixtures were selected as shown in Table 3 .

\subsection{Multi-Sized Powder Batch Forming and Sinter- ing}

For all three powder mixture batches, respective slips were prepared, solid casted, and sintered under the same conditions. ${ }^{15)}$ The dispersant, binder, plasticizer, anti-foaming agent, and dispersion medium used to prepare the aqueous alumina slip were APC (ammonium polycarbonate, Ceraperse $5468 \mathrm{CF},\left(\left(\mathrm{NH}_{4}\right)_{2} \mathrm{CO}_{3}\right) \mathrm{n}, 40 \%$ liquid, specific gravity 1.15, San Nopco Korea Ltd., Korea), PVA-205 (polyvinyl alcohol, $\left(\mathrm{CH}_{2} \mathrm{CHOH}\right) n$, specific gravity 1.19 - 1.31, Kuraray Co., Ltd., Japan), PEG-400 (polyethylene glycol-400, $\left(\mathrm{C}_{2} \mathrm{H}_{6} \mathrm{O}_{2}\right) \mathrm{n}$, Mw 360 - 440, Guoli Chem. Co., Ltd., Korea), (DB-110A, Dow Corning, USA), and ultrapure water, respectively. The amount of additive added was a specific weight ratio with respect to the 48 vol\% alumina powder (Table 4); this was followed by ball milling to prepare the aqueous slip.

The alumina powder, water, dispersant, and spherical alumina underwent primary ball milling for mixing at 180 rpm for $6 \mathrm{~h}$ in a plastic container (Nalgene, Nalgene Labware, USA); this was followed by secondary mixing for an additional $1 \mathrm{~h}$ after adding the plasticizer, binder, and anti-foaming agent. Vacuum degassing was carried out during the mixing of the aqueous alumina slip and mixture was then poured into a plaster mold with a rectangular parallelepiped space to perform solid casting with dimensions of $16 \times 35 \times 65 \mathrm{~mm}$. The fabricated green body was dried at $80 \%$ relative humidity and $25^{\circ} \mathrm{C}$ inside a constant tempera-

Table 4. Aqueous Alumina Slip Composition for Solid Casting

\begin{tabular}{cccc}
\hline \multirow{2}{*}{$\begin{array}{c}\text { Solid content } \\
\text { (vol\%) }\end{array}$} & \multicolumn{3}{c}{ Organic additives in solid (wt\%) } \\
\cline { 2 - 4 } & $\begin{array}{c}\text { APC-5468CF } \\
\text { dispersant }\end{array}$ & $\begin{array}{c}\text { PVA-205 } \\
\text { binder }\end{array}$ & $\begin{array}{c}\text { PEG-400 } \\
\text { plasticizer }\end{array}$ \\
\hline 48 & $0.3(0.4)^{*}$ & 0.5 & 0.5 \\
\hline
\end{tabular}

"Mono-sized batch: 0.4, Double-sized batch: 0.3, Triple-sized batch: 0.3 
ture and humidity drying oven. Green bodies that were determined to have completed the drying process were then subject to the sintering schedule, taking into consideration the pyrolysis temperature range of organic matter. ${ }^{15)}$ Sintering was carried out for $4 \mathrm{~h}$ while maintaining the maximum temperature of $1650^{\circ} \mathrm{C}$.

\subsection{Property Analysis}

The particle sizes of the alumina raw material powder and grinded powder were analyzed using a particle size analyzer (Master Sizer 2000, Malvern Instrument, United Kingdom). In order to minimize particle agglomeration, the powder was sonicated for 20 minutes and measurements for analysis were taken 10 times. For the solid casted body, the mass loss with respect to time was measured through the drying process at $80 \% \mathrm{RH}$ and $25^{\circ} \mathrm{C}$ to investigate the drying rate, which was expressed as the ratio with respect to the mass right after the forming. For the green body density, the volume and dry weight were measured and the sintering density was investigated by determining the relative density in relation to the theoretical density $\left(3.98 \mathrm{~g} / \mathrm{cm}^{3}\right)$ by measuring the bulk density using the Archimedes principle (KS L ISO 18754). The microstructure of the powder was observed using FE-SEM (JSM-6500F, JEOL, Japan) by placing the powder on a tape and conductively coating the surface of the green body. The microstructure of the sintered body was observed after carrying out a final polishing using a $1 \mu \mathrm{m}$ diamond paste and thermal preheating at $1550^{\circ} \mathrm{C}$.

\section{Results and Discussion}

\subsection{Alumina Raw Material Powder Properties}

In order to produce an optimum micro-filling green body through solid casting, 2 commercial alumina powders were ball milled while controlling the average size so as to form a spherical starting powder. The irregular morphology observed for the raw material powder became spherical and fine through the abrasive ball milling process (Fig. 3). This result was due to the abrasion caused by the collisions between the particles, balls and powder, and inner wall and powder during the ball milling process.

The intended average sizes of the host powder (H powder), secondary powder (O powder), and tertiary powder ( $\mathrm{T}$ pow-

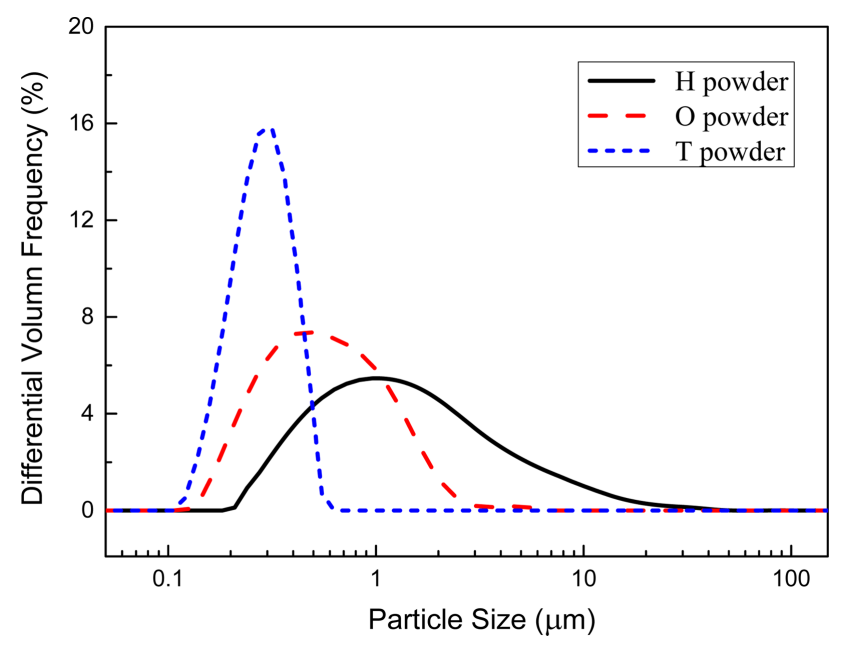

Fig. 4. Particle Size Distributions of Milled Alumina Powder.

der) were $1.36,0.56$, and $0.31 \mu \mathrm{m}$, obtained through milling of the commercial alumina raw material powders. Fig. 4 and Table 5 show the particle size distribution of the milled alumina powder and specific particle size distribution values. The milling process reduced the volume fraction of coarse grains and made the powder finer so that the particle size distribution was relatively narrower than that of the commercial raw material powder and exhibited the characteristics of a normal distribution. It was found that the specific values of the size distribution were similar to the intended sizes.

\subsection{Solid Casted Green Body Properties}

For the green body produced using solid casting, the temperature and humidity during the drying process have to be

Table 5. Three X-axis Values in Size Distribution Curve of Milled Alumina Powder

\begin{tabular}{cccc}
\hline \multirow{2}{*}{ Nomination } & \multicolumn{3}{c}{ Particle size $(\mu \mathrm{m})$} \\
\cline { 2 - 4 } & $\mathrm{d}(0.1)$ & $\mathrm{d}(0.5)$ & $\mathrm{d}(0.9)$ \\
\hline H powder & 0.45 & 1.36 & 4.57 \\
O powder & 0.30 & 0.56 & 1.44 \\
T powder & 0.20 & 0.31 & 0.45 \\
\hline
\end{tabular}

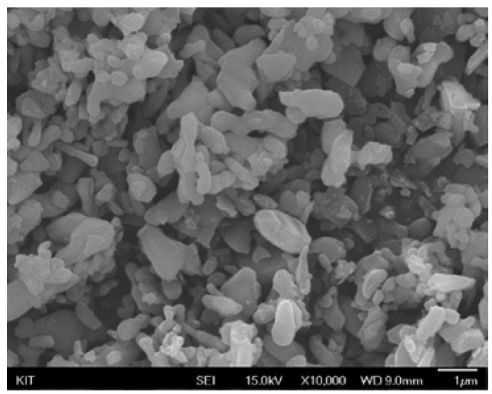

(a)

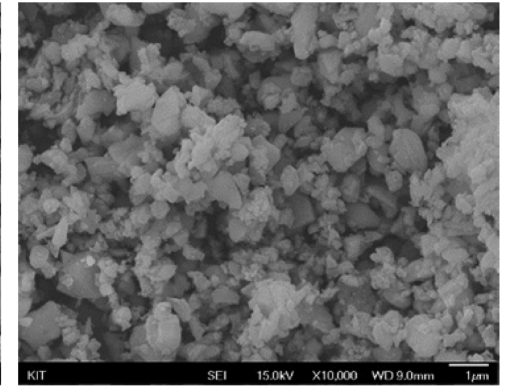

(b)

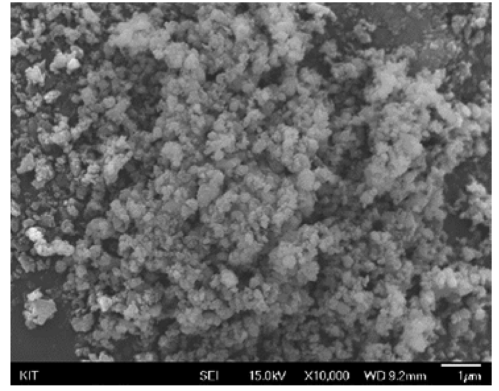

(c)

Fig. 3. Microstructures of milled alumina powder: (a) $\mathrm{H}$ powder, (b) $\mathrm{O}$ powder, and (c) $\mathrm{T}$ powder. 


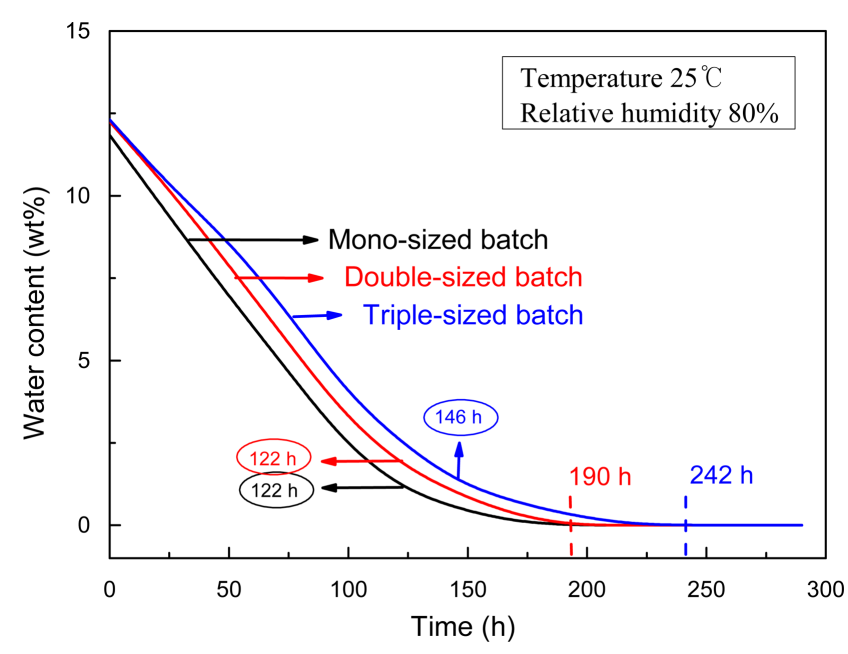

Fig. 5. Drying rates of cast body as a function of time at $25^{\circ} \mathrm{C}$ with $80 \%$ humidity.

appropriately maintained to minimize internal stresses due to differences in shrinkage rate of different parts because the green body contains polymers and moisture. ${ }^{15,16)}$ Fig. 5 shows the green body moisture content decrease plot during the drying process at $80 \% \mathrm{RH}$ and $25^{\circ} \mathrm{C}$.

The triple-sized batch green body with a relatively high amount of fine powder added required the greatest amount of time at $242 \mathrm{~h}$ for the moisture content of the green body to plateau. The mono-sized batch and double-sized batch green bodies took $190 \mathrm{~h}$ for the drying process to complete. The constant drying rate period, where the slope of the moisture content decrease curve becomes constant, sees the surface of the green body remain wet as the moisture travels from the interior to the surface due to the capillary force and surface tension generated between the fine particles when moisture evaporation occurs. ${ }^{14-15)}$ This constant drying rate period range was longest for the triple-sized batch green body at $146 \mathrm{~h}$, which was $122 \mathrm{~h}$ longer than those of the other batch green bodies. This result was thought to be due to the filling fraction increase as small gaps between the large particles composing the green body were filled with fine particles, making it difficult for the internal moisture of the green body to move to the surface. When the constant drying rate period ends, the moisture content of the green body decreases drastically and the falling drying rate period of the curve begins. This falling drying rate period has been reported to be dominated by internal diffusion. ${ }^{14-15)}$ Therefore, internal diffusion becomes difficult for the triple-sized batch with relatively high fine particle fraction, resulting in the longer drying time.

Figure 6 shows the microstructure of the solid casted green body from the multi-sized powder mixture batch. The mono-sized batch green body had a green density of $60.3 \%$ (Fig. 7) and numerous gaps between the particles were observed because the composition was only coarse grains. On the other hand, the double-sized batch and triple-sized batch green bodies revealed fine particles within the coarse grain gaps. The microstructures showed higher relative densities of $60.6 \%$ and $61.4 \%$ (Fig. 7) due to the reduced void fractions.

\subsection{Solid Casted Sintered Body Properties}

Figure 7 compares the green density and sintered body density after solid casting and sintering for $4 \mathrm{~h}$ at $1650^{\circ} \mathrm{C}$ to those of the multi-sized powder mixture batch. The sintered body produced from the mono-sized batch composed only of coarse grains showed a relative density of $93.8 \%$, while those of the sintered bodies produced from the double-sized and triple-sized batches with added fine particles were

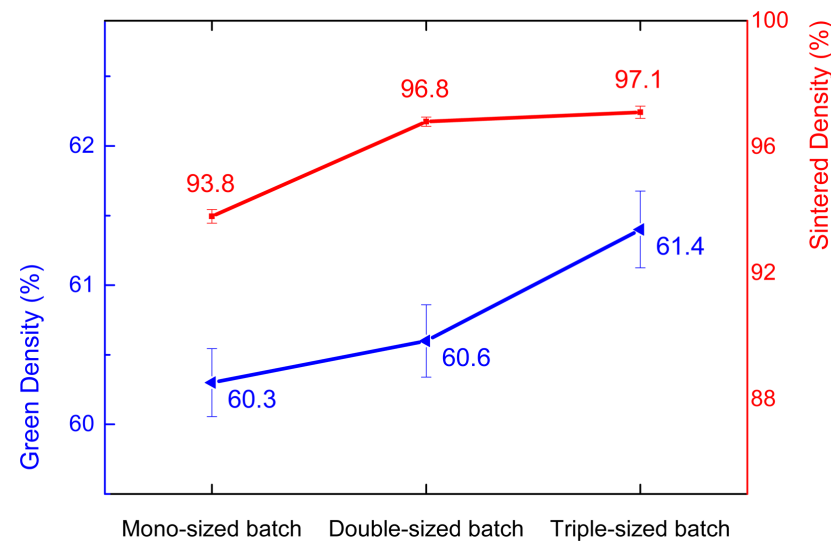

Fig. 7. Relative green and sintered densities obtained from different powder batches.

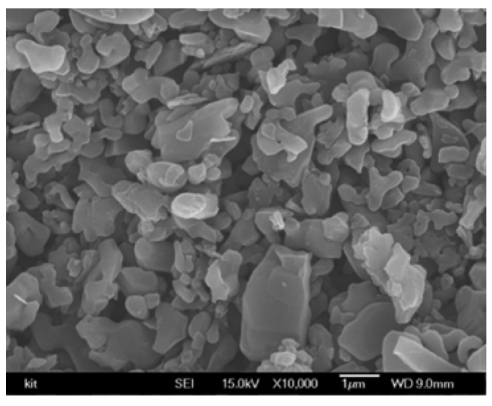

(a)

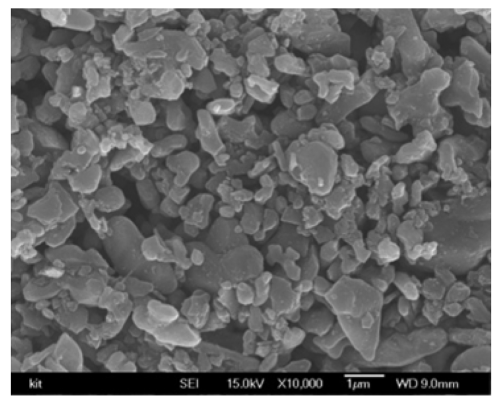

(b)

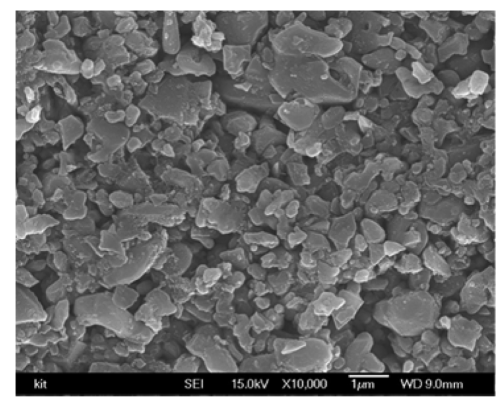

(c)

Fig. 6. Microstructures of green body manufactured from multi-sized powder mixtures: (a) mono-sized, (b) double-sized, and (c) triple-sized batches. 


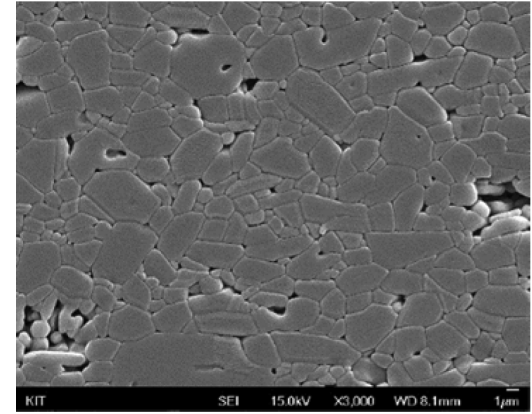

(a)

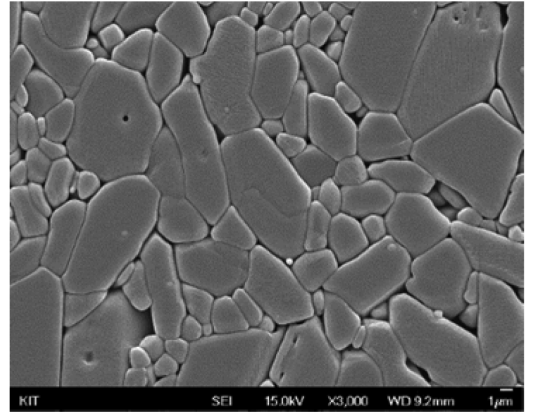

(b)

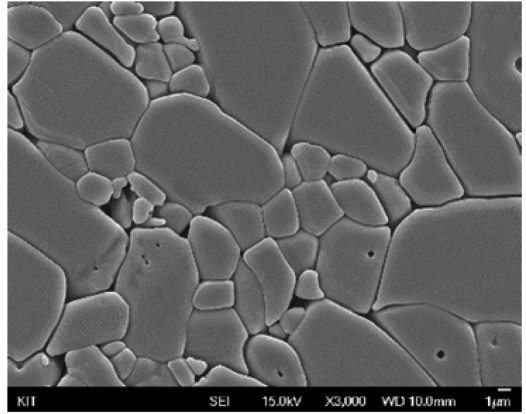

(c)

Fig. 8. Microstructures of $1650^{\circ} \mathrm{C}$ sintered body manufactured from multi-sized powder mixtures: (a) mono-sized, (b) double-sized, and (c) triple-sized batches.

$96.8 \%$ and $97.1 \%$, respectively, representing increases of more than $3 \%$.

Figure 8 shows the microstructure of the $1650^{\circ} \mathrm{C}$ sintered body from the multi-sized powder mixture batch. The sintered body fabricated from the mono-sized batch with only coarse powders exhibited a microstructure corresponding to 93.8\% density, for which densification was not completed and large inter-granular pores of a few microns were observed. On the other hand, the microstructures of the green bodies from the double-sized and triple-sized batches with added fine particles showed completed densification with no voids between the large particles; increased average particle size was observed due to extended grain growth. ${ }^{17}$ )

The mono-sized batch sintered body was composed only of coarse grains, so the sintering driving force is relatively low and the green body contained large voids that required long diffusion lengths for densification; thus, it was determined that densification was not sufficiently carried out due to the sintering conditions used in this study. In contrast, the double-sized and triple-sized batches with added fine particles included powder of relatively high sintering driving force and this increased the number of contact points between particles, while void sizes decreased within the green body, so that densification was completed through sintering and activated grain growth, resulting in increased average particle size.

\section{Conclusions}

Commercial alumina powders with wide particle size distribution and irregular morphologies underwent ball milling and planetary ball milling to process the powder and produce a narrow particle size distribution and spherical particles. It was found that the multi-sized alumina powder mixture batch with added fine particles of sizes corresponding to the octahedral and tetrahedral voids formed via optimum micro-filling with spherical mono-sized particles had outstanding formability and sinterability. Compared to the mono-sized powder batch, the solid casted green body fabricated from the fine particle added powder batch showed relatively extended constant drying rate period and drying completion time, while the green density also increased. The alumina body sintered at $1650^{\circ} \mathrm{C}$ also exhibited relative improvements in the density and densification when using the fine particle added powder batch.

\section{Acknowledgments}

This research was supported by the sabbatical year research grant of Kumoh National Institute of Technology.

\section{REFERENCES}

1.J. Zheng, P. F. Johnson, and J. S. Reed, "Improved Equation of the Continuous Particle Size Distribution for Dense Packing," J. Am. Ceram. Soc., 73 [5] 1392-98 (1990).

2. C. C. Furnas, "Grading Aggregates, I-Mathematical Relations for Beds of Broken Solids of Maximum Density," Ind. Eng. Chem., 23 [9] 1052-58 (1931).

3. F. O. Anderegg, "Grading Aggregates, II-The Application of Mathematical Formulas to Mortars," Ind. Eng. Chem., 23 [9] 1058-64 (1931).

4. R. K. Mc Geary, "Mechanical Packing of Spherical Particles," J. Am. Ceram. Soc., 44 [10] 513-22 (1961).

5. R. M. German, "Prediction of Sintered Density for Bimodal Powder Mixtures," Metall. Trans. A, 23 [5] 1455-65 (1992).

6. S. Taruta and N. Takusagawa, "Slip Casting of Alumina Powder Mixtures with Bimodal Size Distribution," $J$. Ceram. Soc. Jpn., 104 [5] 447-50 (1996).

7. K. K. Lee, "Slip Casting," J. Korean Ceram. Soc., 12 [1] 12-9 (1997).

8. J. A. Lee and J. J. Kim, "Sintering Behavior of Bimodal Size-Distributed Alumina Powder Mixtures," J. Korean Ceram. Soc., 36 [7] 718-24 (1999).

9. S. Tauta, Y. Sakurai, N. Takusagawa, K. Okada, and N. Otsuka, "Slip Casting of Alumina Powder Mixtures with Bimodal Size Distribution-Influence of Particle Size Difference between Fine and Coarse Powders on Packing and Con- solidation Process," J. Ceram. Soc. Jpn., 108 [3] 25460 (2000).

10. F. M. Tiller and C.-D. Tsai, "Theory of Filtration of Ceramics: 1. Slip Casting," J. Am. Ceram. Soc., 69 [12] 882-87 (1986). 
11. T. K. Sherwood, "The Drying of Solids-I," Ind. Eng. Chem., 21 [1] 12-6 (1929).

12. T. K. Sherwood, “The Drying of Solid-II," Ind. Eng. Chem., 21 [10] 976-80 (1929).

13. T. K. Sherwood, "The Drying of Solid-III," Ind. Eng. Chem., 22 [2] 132-36 (1930).

14. J. S. Reed, "Drying," pp. 545-61 in Principles of Ceramics Processing, Willey, New York, 1995.
15. K.-S. Cho, I.-B. Song, and J. Kim, "Homogeneous Shape Forming of Alumina by Pressure-Vacuum Hybrid Slip Casting," J. Korean Ceram. Soc., 49 [6] 592-600 (2012).

16. J. L. Amoros, E. Sanchez, V. Cantavella, and J. C. Jarque, "Evolution of the Mechanical Strength of Industrially Dried Ceramic Tiles during Storage," J. Eur. Ceram. Soc., 23 [11] 1839-45 (2003).

17. R. M. German, Powder Metallurgy \& Particulate Materials Processing; pp. 155-83, Metal Powder Industries Federation, 2005. 